\title{
Managing Organizational and Management Challenges in India
}

Chaturvedi J*, Agarwal A and Patodia A

Abhinav Arts NATA Academy I, Abhinav Arts Research Development and Academic Society, Jaipur, Rajasthan, India

\begin{abstract}
India contributes $5 \%$ to the World GDP and is the fourth major contributor to it. Indian companies have proven their global presence in the fields of manufacturing and Real estate and Hotel industry, Agriculture and Construction fields.

Any Organization has stakeholders like Society, Employees, Management, Suppliers and Customers and the success depends on the fulfillment of expectations of all these stakeholders. We did a survey to find out challenges related to all these stakeholders. Building Core Competency, Maintaining Motivation of Employees, Customer Delight, Instilling Values and Ethics, Knowledge Management and Globalization emerged as the major through the survey. We did brainstorming to find out why these are a challenge and what can be a probable solution to deal with these challenges and achieve inclusive growth.

We went through the case studies of various successful organizations to formulate a Believe model which stands for be leaders in Innovation, Education and Values and Ethics. We believe that our modal will help Organizations and Management to deal with various challenges in the various phases of its existence. Like a child grows up and overcomes different challenges in the various phases of his/her life an organization also has to deal with different challenges at different phases. The importance of a challenge varies continuously as an organization ages from a new entrant in the market to a big player.
\end{abstract}

Keywords: Believe; Leadership; Innovation; Education; Values; Ethics

\section{Introduction}

\section{India: Aspiring high or living low}

"There are two India's in this country, one India is training at the leash eager to spring forward and live up to all the adjectives the world has been showering upon us, the other India is the leash. One India says give me a chance and I will prove myself the other India says prove yourself first and may be then you have a chance. One India lives in the optimism of our hearts the other India lacks in skepticism of our minds. One India wants the other hopes. One India leads the other follows. These conversions are on the rise, with each passing day more and more people from the other India are coming over to this side and quietly when the world is not looking a pulsating dynamic new India is emerging an India whose faith in success is far greater than its fear of failure [1].

For years we have been projecting India to be a superpower, the question now is when will we become one. We have been promising to ourselves that we will fight poverty, we will improve our education system the question now is will we ever be able to? The world terms us as a growing country, we now need to think if we are really growing? All these questions and many more directly question the strategies and policies our government has made for us. But on an outset, have we ever thought how efficiently our Organizations have driven on the scarce policies we have.

\section{So what does an organization expect?}

With projected GDP growth of $7.20 \%$ [2] and with 10 of the 30 fastest growing urban areas [3] of the world, there is very little scope for an industry to not start thinking about the potential and opportunities India has to offer. Residential projects multiplying, new offices opening up, malls, hospitals, Shops, restaurants, schools, Sports clubs everything is just multiplying. Resources in India are in no way less than what is required, be it in monetary terms or in terms of labor.

To place India's demographic potential into some perspective, the projected UN population increase from 2000 to 2020 is $310 \mathrm{mn}$, about the same size as the US population today. India will in effect create the equivalent of another US, and for those of working age between 2000 and 2020, India will create the equivalent of the combined working population of France, Germany, Italy and the UK [4] (Figure 1).

On economic front Foreign Direct Investments (FDI), after all the hues and cries of the toughest financial year, have maintained the same level as of 2008-2009 (with an increase of 0.3\% from INR 123,025 crore to INR 123,377 crore) $[5,6]$. Capital and manpower being the strengths, India is on its way to deliver just what the world wants. As more and more customers become cost and quality conscious, expectations for a low cost - High performance product increases (Figure 2).

These findings are not only validated from the survey, live examples like those of Jaipur - foot [7] have gone way ahead in proving what the demands of the world really are. Taking a holistic view, such day to day innovations are not only motivating the Indian entrepreneurs but they are giving everyone in the country a chance to dream.

To not let this power of dreaming turn into a nightmare for the country, it is very important for India to address its challenges of literacy, women empowerment and corruption. Other than the long - term challenges of an Organizations in India, those that can be seen in the graph below, there is a much larger challenge of upbringing the society (Figure 3 ).

Top six challenges which Organizations in India are facing today are:

*Corresponding author: Chaturvedi J, Abhinav Arts NATA Academy I, Abhinav Arts Research Development and Academic Society, Jaipur, Rajasthan, India, Tel: +918696643325, +919079709243; E-mail: joohichaturvedi2001@gmail.com

Recieved April 25, 2018; Accepted June 26, 2018; Published July 02, 2018

Citation: Chaturvedi J, Agarwal A, Patodia A (2018) Managing Organizational and Management Challenges in India. J Entrepren Organiz Manag 7: 235. doi: 10.4172/2169-026X.1000235

Copyright: ( 2018 Chaturvedi J, et al. This is an open-access article distributed under the terms of the Creative Commons Attribution License, which permits unrestricted use, distribution, and reproduction in any medium, provided the original author and source are credited. 
Citation: Chaturvedi J, Agarwal A, Patodia A (2018) Managing Organizational and Management Challenges in India. J Entrepren Organiz Manag 7: 235. doi: 10.4172/2169-026X.1000235

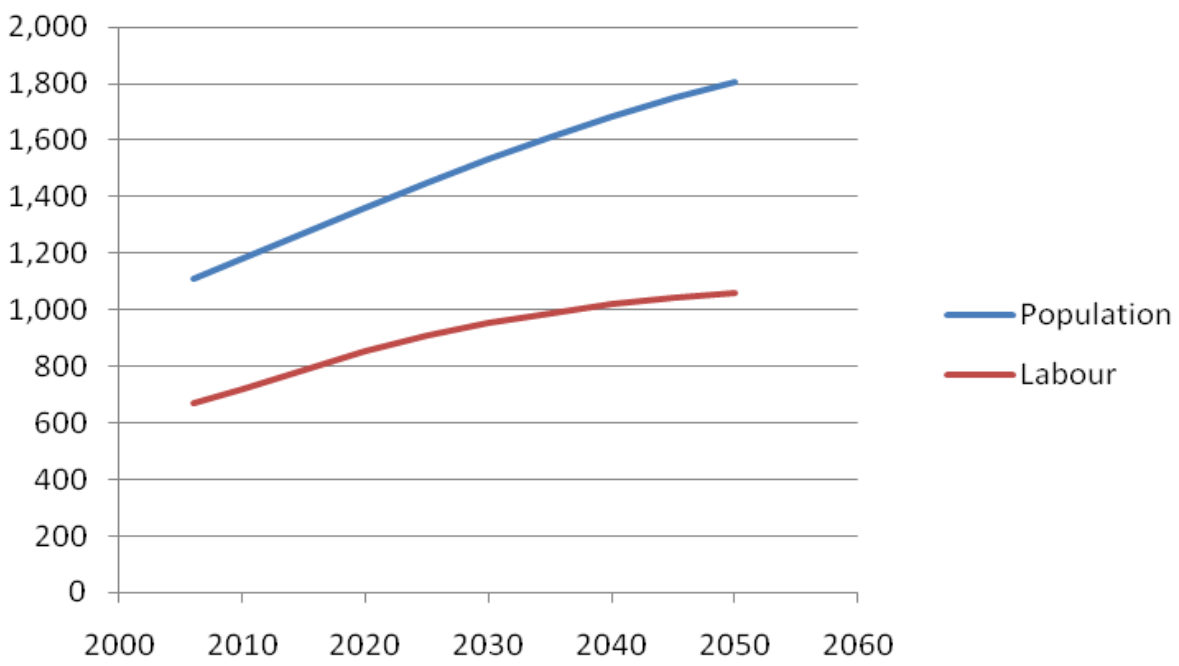

Figure 1: Projected population and labour of India.

As A Customer What is Your Utmost Demand From an Organization

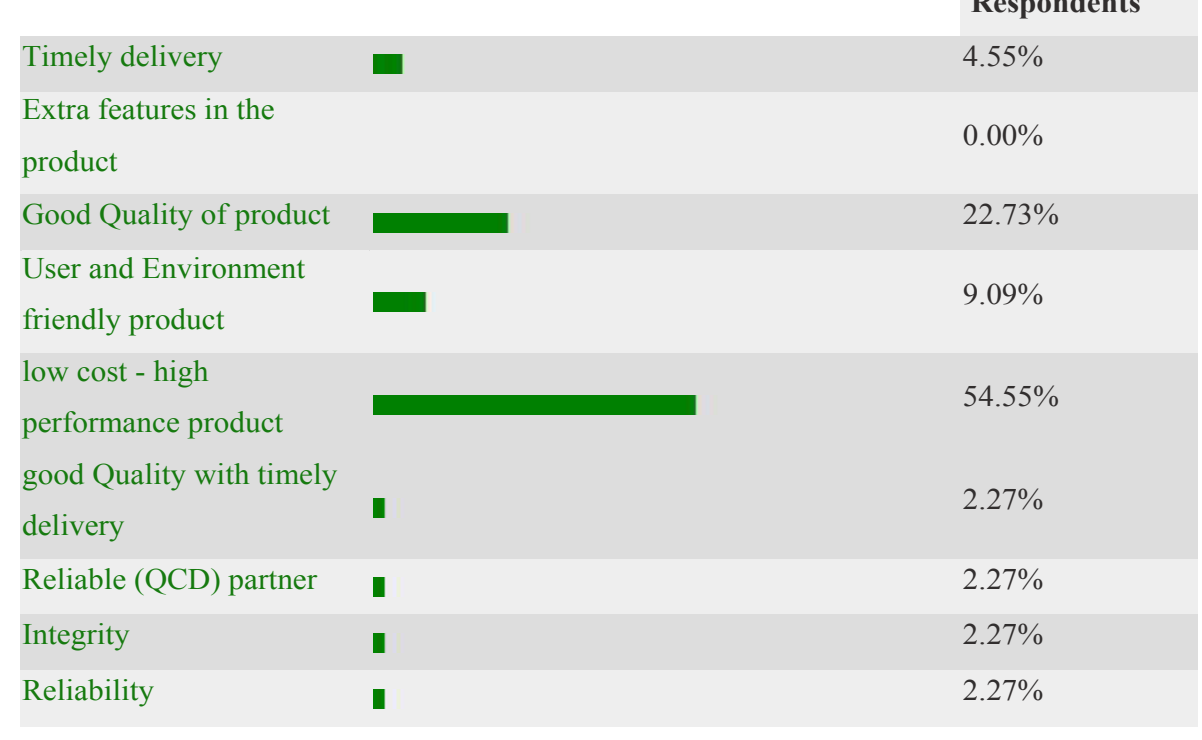

Figure 2: Survey Result - Customer Demand.

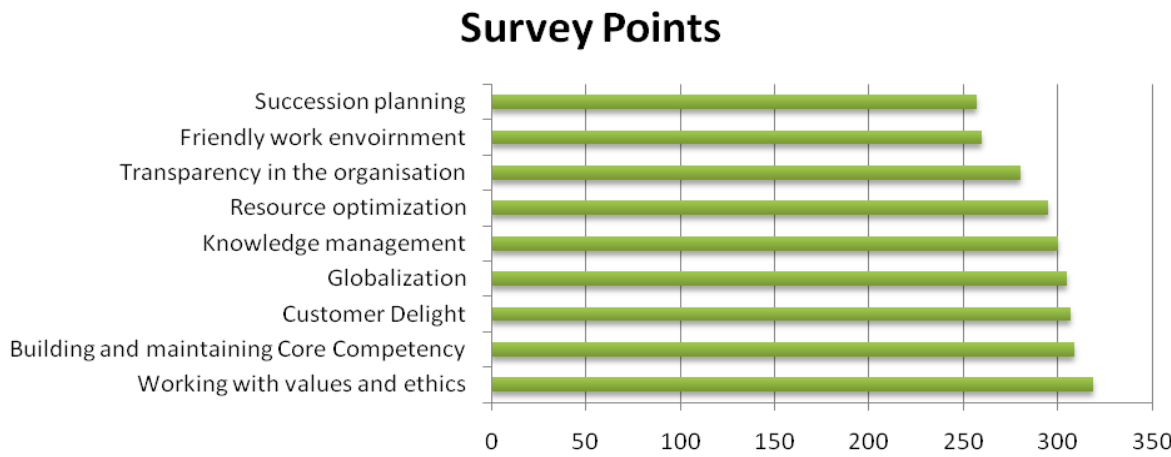

Figure 3: Survey Result - Challenges. 
- Working with values and ethics

- Building and maintaining Core Competency

- Customer satisfaction and Delight

- Globalization

- Maintaining motivation of Employees, and

- Knowledge management.

\section{Building and maintaining core competency}

"Focusing on core competencies creates unique, integrated systems that reinforce fit among your firm's diverse production and technology skills - a systematic advantage your competitors can't copy" - Prahlad [8].

A successful person is someone who does what he does in the best possible way. When a person recognizes his strengths he starts grooming them, builds expertise in them and thus excels in it. Similarly for Organizations, some processes, policies and approaches become its strengths. When an Organization starts strengthening them they start becoming standards and with continuous improvements they become benchmarks. These processes or practices of Organizations then become its core competency on which the company dwells.

Why does one need to build core competency?

Why 1: To achieve operational excellence.

Why 2: To capture and expand its market.

Why 3: To increase profitability.

The root cause of need for building core competency is to increase profitability by standing out from others; one way of doing this is by achieving operational excellence. Maturity in production systems like those with Lean manufacturing and Waste Management leads to such operational excellence. A key performance indicator of where the Organizations stands in terms of its competency can be judged by figures of its market share in that specific market or by counting the Mergers and Acquisitions directly related to the field they are in Figure 4.

Building these competencies is one challenge and sustaining them is another. Once the competency is build, Organizations should have methods to sustain them, these methods further deal with other challenges like that of knowledge management.

\section{Globalization}

"Diversity is the one true thing we all have in common. Celebrate it every day"- Anonymous.

It's a phenomenon where market is open for all nations to come and sell their products. It's a process of increasing the connectivity and interdependence of the world's markets and businesses.

Why Globalization is a challenge?

Why 1 : Possibility of reduction in profit.

Why 2: Threat to Customer base.

Why 3: More competitors in market selling the same product.

With the opening of gates all across the globe, the international market is experiencing a shift in market in terms of technology, price, quality of products and services offered to the customer. New solutions are coming which make it easier for people to travel, communicate, and do business internationally for example in telecommunications infrastructure and rise of the internet.

But in turn the customer is benefited by getting more options in terms of cost and quality. Also there is mutual coexistence of different cultures which is promoted in society which results in exchange of attributes.

Is Globalization beneficial to all countries or is it a monopoly of few?

The benefits of globalization are never evenly distributed across the
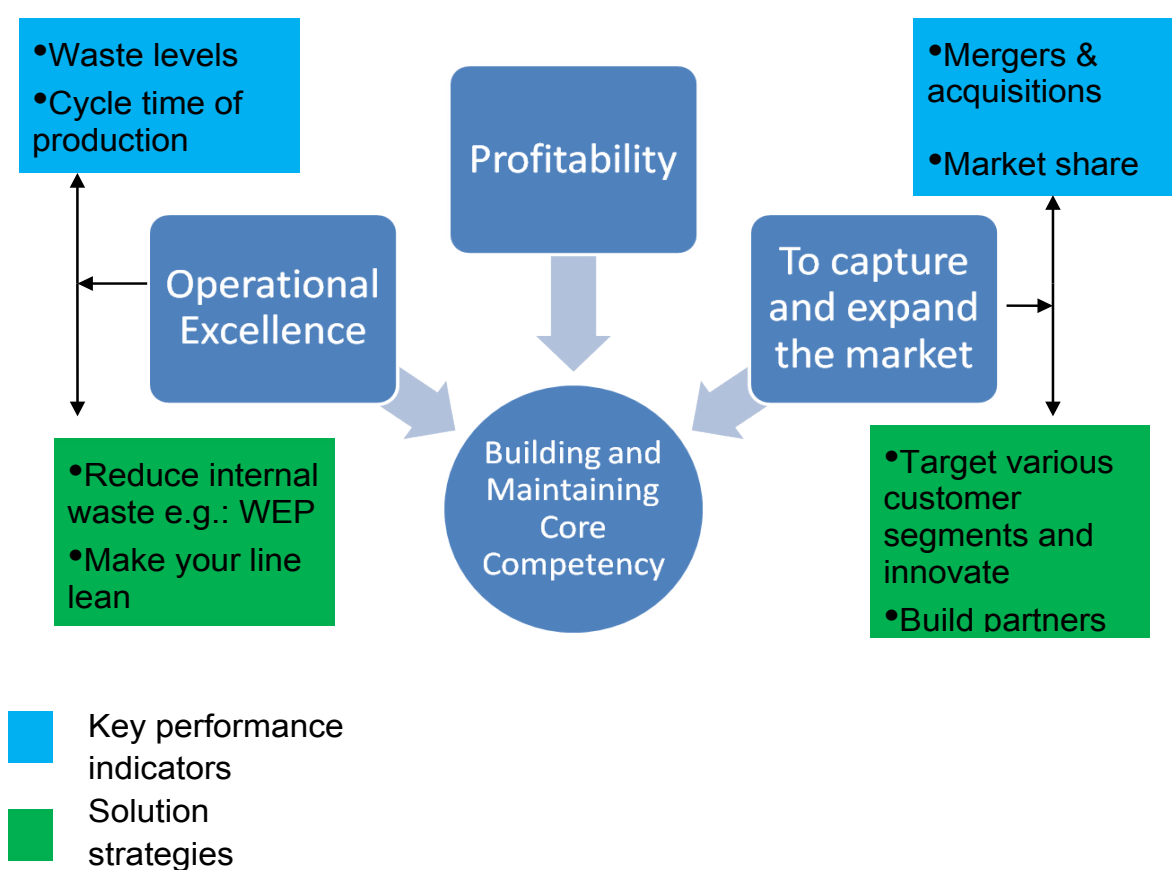

Key performance indicators

Solution strategies

Figure 4: Key performance indicators and strategies for core competency. 
Citation: Chaturvedi J, Agarwal A, Patodia A (2018) Managing Organizational and Management Challenges in India. J Entrepren Organiz Manag 7: 235. doi: 10.4172/2169-026X.1000235

Page 4 of 11

whole economy of a given country. There are always winner and losers.

The short term winners and losers of globalization are not necessarily the same as the parties that experience long term gains and losses. The actual effect of globalization can be seen over a period of time as the market demand keeps on fluctuating (Figures 5 and 6).

\section{Globalization in India}

Is it necessary to go global or can organizations have the privilege of taking a different stand?

"Those who don't change become obsolete"

Going global is not a choice rather it's the demand of the time and in fact the Globalization in India has benefited many companies in the following ways:

- Increasing in their base of operations.

- Expanding their workforce with minimal investment

- Providing new services to a broad range of consumers.
India has the potential to withstand the effect of globalization and discover new oceans.

Mechanisms of using diversity as an asset would be in terms of creating worldwide employment opportunities, location changes of manufacturing units based on long term business objectives or just inter-cultural workshops to enhance better cooperation and understanding. Diverse cultures have demonstrated higher potential to take up challenges, in a better way than those without diverse cultures.

Looking at the initiative at Bosch, this is in-built in one of the several values as "Cultural Diversity". Having a presence in total of 150 countries of which 60 are regional locations outside Europe and 286,000 associates worldwide producing wide variety of products like Automotive components, securing systems, packaging machines, home appliances, software and so on is a symbol of a truly multi-cultural, multi-location and multi-product organization [9].

Indian companies are rapidly gaining confidence and are themselves now major players in globalization through international expansion. From steel to Bollywood, from cars to IT, Indian companies are setting

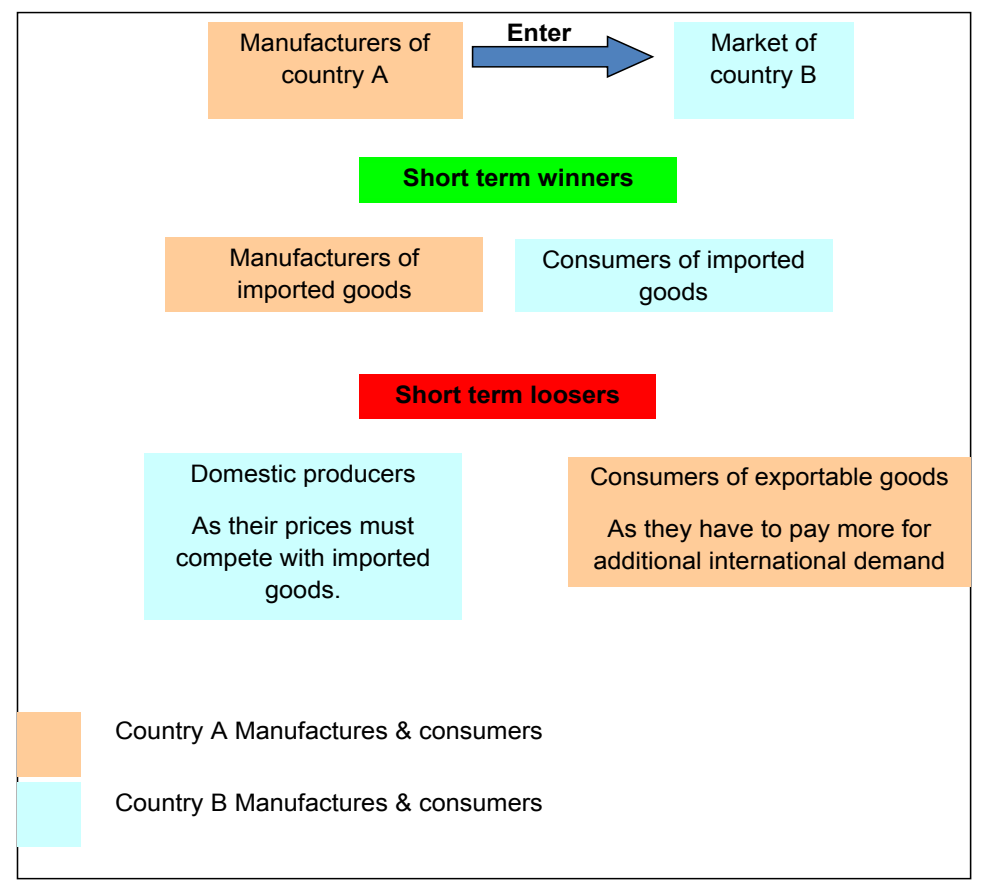

Figure 5: Globalization: Winners \& Losers.

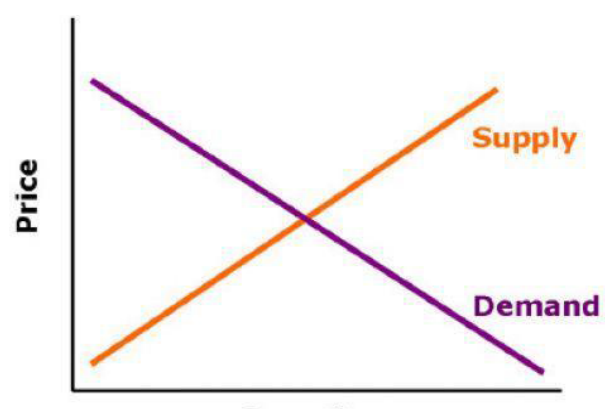

Quantity

Figure 6: Effects of globalization. 
themselves up as powerhouses of tomorrow's global economy.

\section{Proposed strategy for globalization}

As we have seen, it's the demand of the time to go global and we have been benefited also by doing so.

In order to be a part of long term winners, we need to pro-actively interpret the market trends in terms of customer demand and also keep an eye on a global scale as to which organizations can be a competitor in future.

To compete on a global scale the following need to be focused upon:

1) Low cost high quality product - In order to maintain the customer base, we need to serve the customer with a quality product with a competitive cost. This can be achieved through continuous reduction in the wastes through CIP.

e.g.;- Increased quality and features with lower cost in electronic equipment's.

2) Focus on R\&D: New ways and methods to be explored in order to find alternate solutions which are more robust in terms of cost and quality.

e.g.:- The launch of world cheapest car "Nano" by Tata has undergone good amount of research before the dream finally came true.

\section{Customer delight}

"A customer is the most important visitor on our premises; he is not dependent on us. We are dependent on him. He is not an interruption in our work. He is the purpose of it. He is not an outsider in our business; he is a part of it. We are not doing any favor by serving him. He is doing us a favor by giving us an opportunity to do so."Mahatma Gandhi [10]. Customer delight is an emotion that customer feels when the Organizations gives a pleasant surprise by delivering affordable quality products beyond customer expectation in time consistently (Figure 7).

\section{Why Customer Delight?}

Why 1: Strengthen the relationships with the buyer (to gain trust and loyalty).

Why 2: To have better business opportunities with the existing customers.

Why 3: To showcase an example so that new customers can be captured.
Why 4: Become leaders in market.

In today's scenario customer satisfaction does not linearly transform into loyalty in terms of business \& purchase, it's time to focus on more intense customer emotions, such as delight (a combination of joy and pleasant surprise). It raises the bar of customer expectations and in turn keeps the Organizations on its toes. Joy is of two types-

1. Real joy which gives the customer the confidence and reassurance that the source of joy is stable and will be available when they want to experience the feeling.

2. Magic joy which is not long term \& customers are worried that something will cut short and will bring them back to reality.

The figure below explains how customer satisfaction to customer delight strengthens the future prospects of an Organizations and its probability of existence (Figure 8).

For delighting our customers we suggest a solution model as shown below (Figure 9).

Outside in Approach: The outside in approach looks at customer complaints \& problems as golden opportunities to improve. Here we need to spend time with the sole purpose of learning how they work, what they value \& what they need. This knowledge not only drives the development of innovative solutions but it also defines value for your organization. Analyze what waste customers are doing e.g. unnecessary movement, excessive scrap, rework, erratic flow, bottlenecks etc. and try to develop solutions for them. Uncover the unarticulated needs that are important and unmet as their insights might be limited by their experiences and reflect only what they know. Capture the voice of the customer by observing how they work in the field, at their sites, using your products or services or those of your competitors [11].

If we can uncover these unstated needs and pain points through observing and listening, we will gain a unique perspective of our customers that our competitors won't have.

Mr. Customer Concept is designed to strengthen the relationships with customers by frequent interactions \& visits and making one person solely responsible to respond to one customer so that customer voice is not unheard and delayed responses can be avoided and quick actions can be taken for all customer complaints (Annexure 1).

Using the above two approaches as inputs we recommend Continuous improvement activities (Quality problem solving, Waste elimination processes, kaizen, and suggestions) in-house so that we innovate our products suitable to the customer and reduce customer problems and raise the Quality standards of the products delivered $[10,12]$.

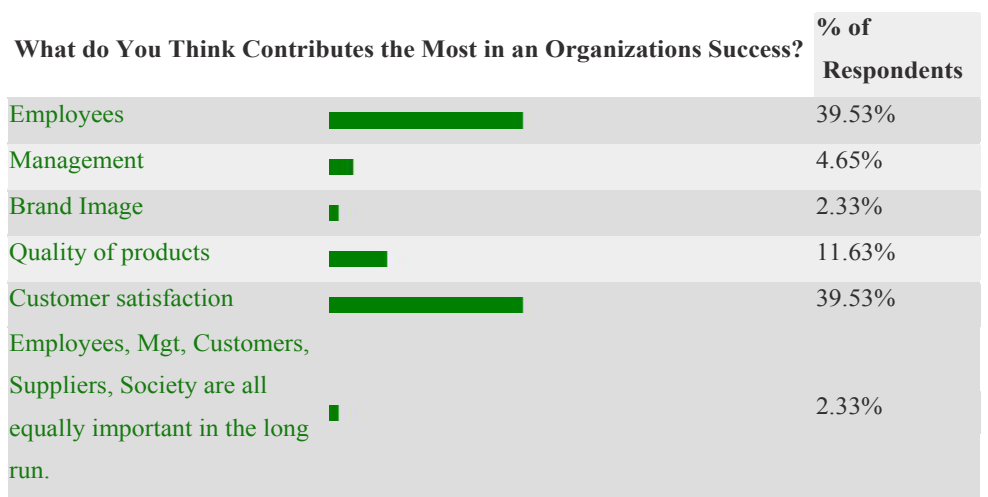

Figure 7: Survey result for contributors of organization success. 


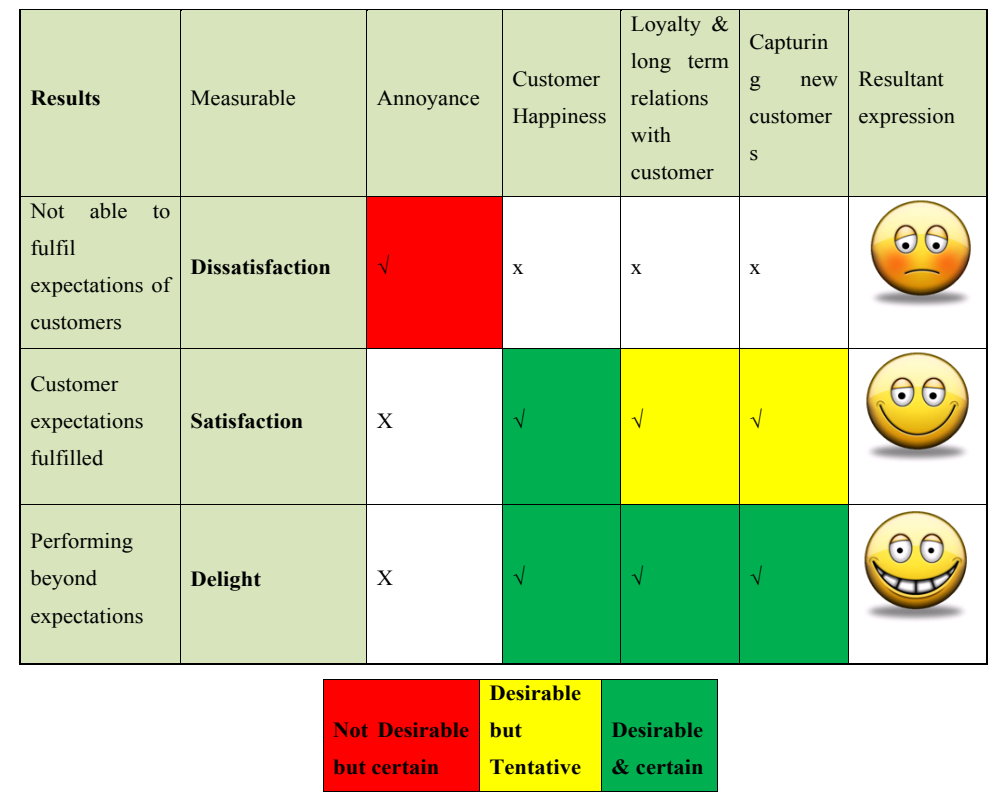

Figure 8: Customer delight matrix.

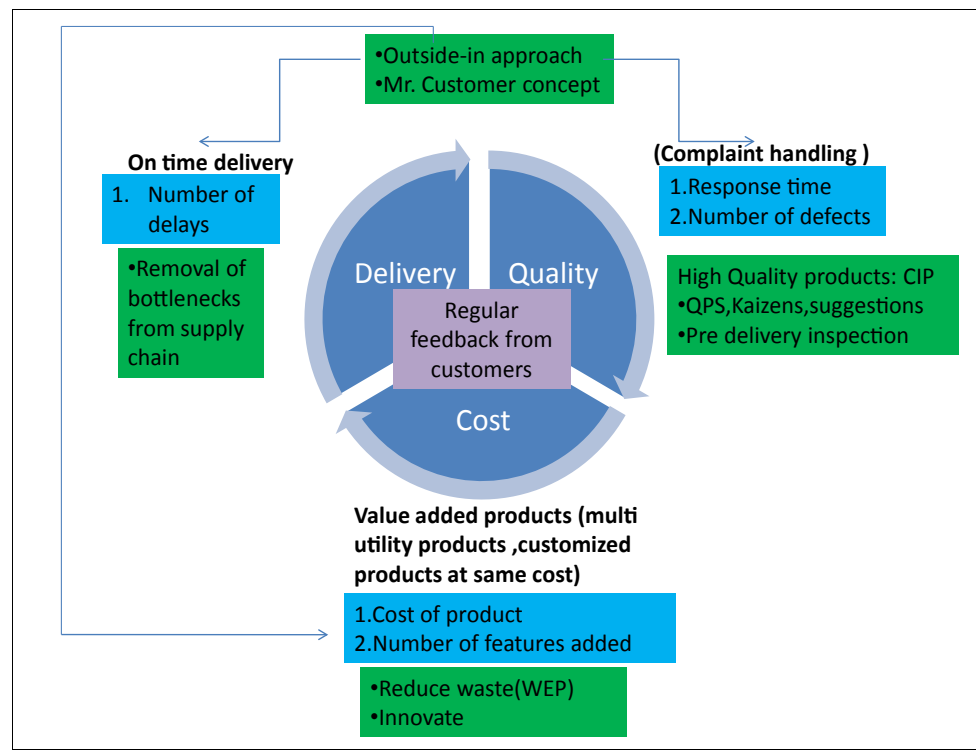

Key performance indicators

Solution strategies

Figure 9: Key performance indicators and key performance results for customer delight.

\section{Maintaining motivation of employees}

"Employees should be treated as assets, not liabilities, who work in human communities that promote trust and respect, and not just profits." Peter Drucker.

"The quality of an organization can never exceed the quality of the minds that make it up".

All Organizations today need a workforce that is striving hard to achieve the targets and is highly motivated at work. Organizations achieve its targets through its most important assets, the employees. So, to have a highly motivated task force giving $100 \%$ all the time is a necessity. But it is a give and take relationship so to gain trust, confidence and loyalty of employees a lot has to be done from the Organizations perspective (Figure 10).

Why does one need to maintain motivation of employees?

Why 1: Employees enjoy their work and give their 100\% 
Why 2: Knowledge banks "employees" stick to the Organizations

As seen from the results of the survey the need of the hour today is to treat people with respect, have a healthy work environment, give them challenging work and provide Decision making authority (Figure 11).

People quality includes leveraging all the three elements viz. intellectual, social and emotional capital of people. This should be worked further at all levels to reach a state of self-actualization. It is really this secret that can produce lasting and profound change to people and organization. Self-actualization is the highest level of selfmotivation and maximized development of an individual which helps to realize the complete potential or in short "becoming everything one is capable of becoming" [1].

Organizations should create necessary conditions and environment for helping individual and groups to identify their potential and draw a road map for improvement. Many organizations have emphasized on the conventional approaches like material or monetary incentives, hierarchical status or management talk as important steps towards improving people quality, but often, they are counter-productive to the

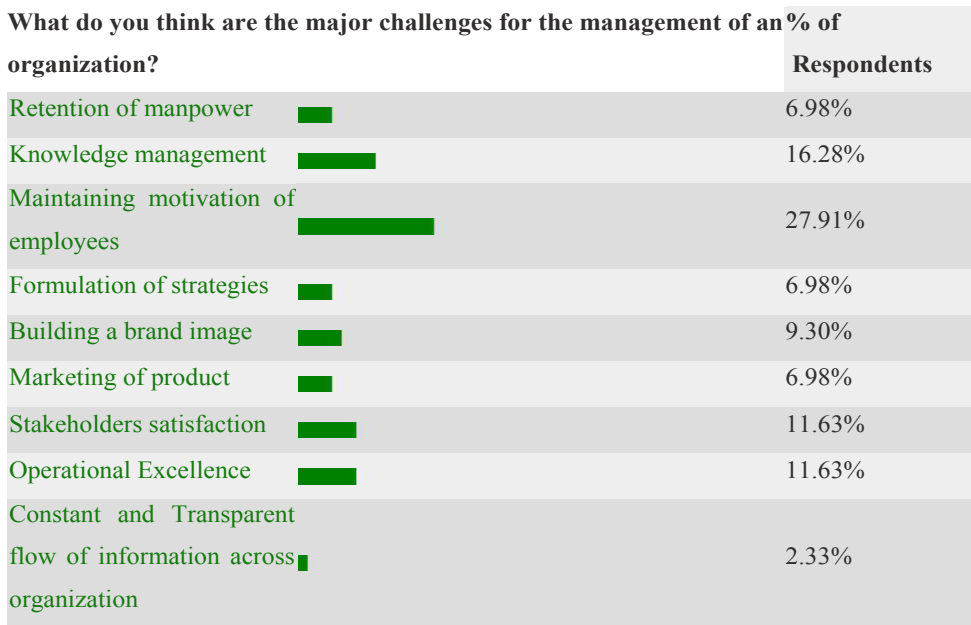

Figure 10: Challenges for management.

What do you expect as an employee of an organization?

(1 - Most Important 5 - least Important )

$\begin{array}{llllll} & 1 & 2 & 3 & 4 & 5 \\ \text { Employee Delight } & 34 \% & 23 \% & 13 \% & 9 \% & 18 \% \\ \begin{array}{l}\text { Growth of society } \\ \text { Healthy work }\end{array} & 9 \% & 25 \% & 37 \% & 16 \% & 11 \% \\ \text { environment } & 34 \% & 25 \% & 9 \% & 16 \% & 13 \% \\ \begin{array}{l}\text { Decision making } \\ \text { authority }\end{array} & 20 \% & 37 \% & 16 \% & 23 \% & 2 \% \\ \begin{array}{l}\text { Exceptional pay scale } \\ \text { Exco }\end{array} & 18 \% & 20 \% & 32 \% & 23 \% & 4 \%\end{array}$

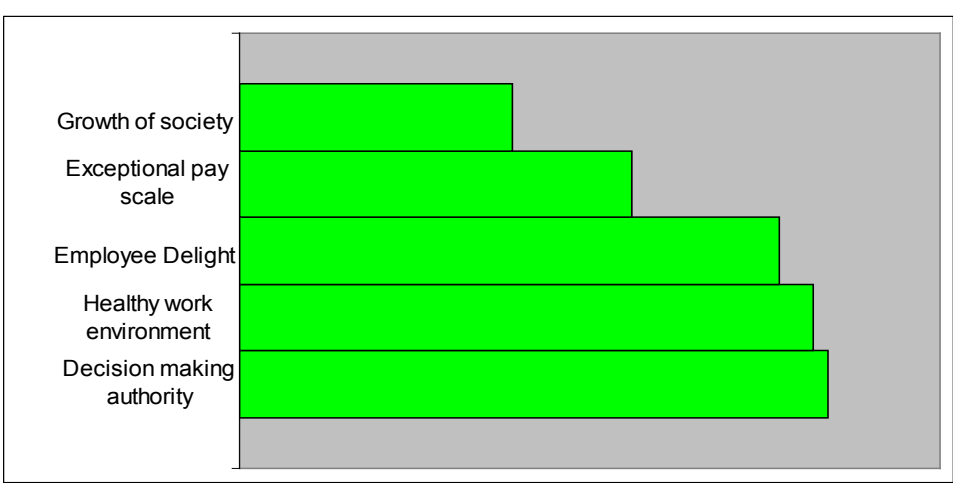

Figure 11: Expectations of an employee. 
Citation: Chaturvedi J, Agarwal A, Patodia A (2018) Managing Organizational and Management Challenges in India. J Entrepren Organiz Manag 7: 235. doi: 10.4172/2169-026X.1000235

Page 8 of 11

goal of achieving the state of self-actualization (Figure 12).

\section{Values and ethics}

The purpose of technology is to comfort human beings. When spiritual values - human values - are ignored and neglected, technology brings fear and destruction instead of comfort. Technology without human values would see nature as a dead object - Sri Sri Ravi Shankar [13].

Why 1: Long term sustenance of the Organizations

Why 2: Contributor in building brand image

People through a strong mentorship process where they are able to realize their full potential on their own and can take conscious decisions and be fully aware of their capabilities and limitations. Also important is to get and give a transparent feedback for continual improvement. They should be enabled to seek balance in their own life and also support and sensitize others in an altruistic way (Figure 13).

Also each individual should be directed towards striking a balance in his/her own life and should also be motivated to develop one target toward the society. What is finally achieved is a mutual win-win situation for the employee and organization leading to the betterment of the society.

When there is an alignment between an organization's values and its employees' values, then people respond by fulfilling their potential and tapping their deepest levels of creativity. This involves moving to a broader group of objectives that are instrumental in meeting shareholder, worker, customer, supplier, community and societal needs [1].

\section{Knowledge Management}

Knowledge is of no value unless you put it into practice - Antov Chekov

\section{Why Knowledge management?}

Why 1: Remove dependency on people, strengthening system dependency

Why 2: Avoiding delays in routine works

\section{Ownership concept}

New individuals to be groomed by experienced professionals

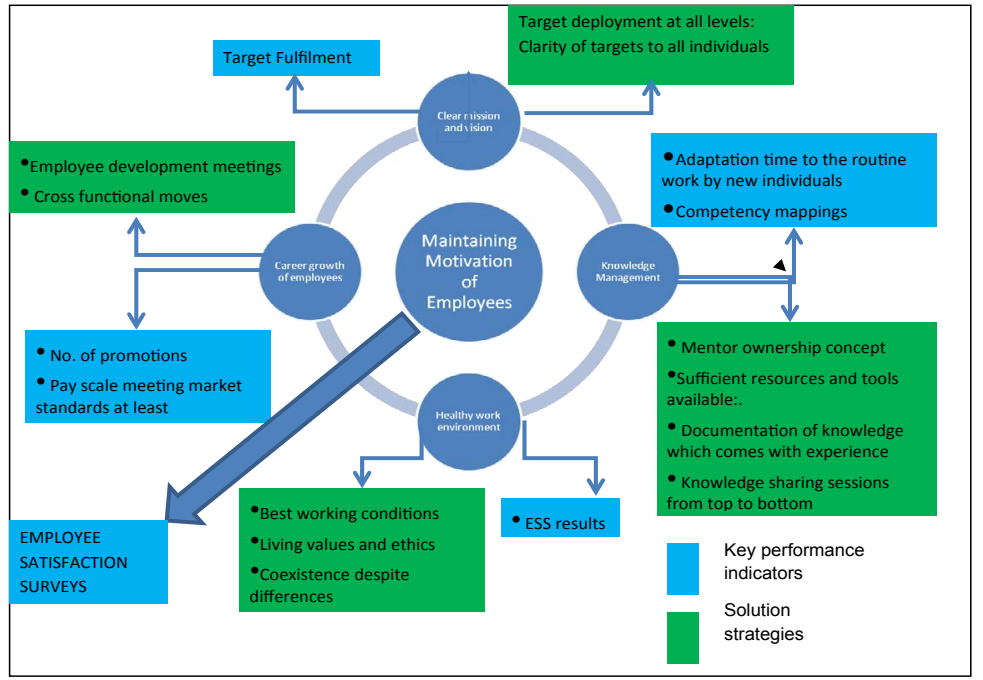

Figure 12: Key performance indicator and strategies for motivation of employees.
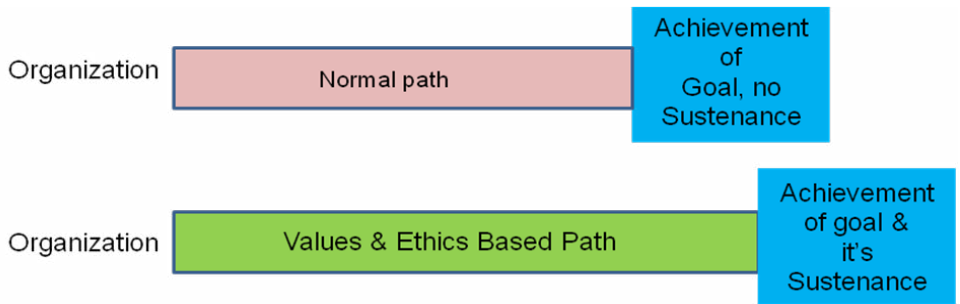

Characteristics'

Adherence to all systems and standards

Partial adherence or no adherence

Figure 13: Path for values and ethics. 
(mentors) who have immense experience and knowledge so that they can transform and mould the inexperienced with their knowledge and talent.

The mentor will be solely responsible for the career growth of the individual and his growth will also be linked to the growth of the mentee.

With globalization happening all around the globe and the number of opportunities multiplying it is very difficult to retain an employee. More than the employee, from an Organizations point of view what is important is the experience and the knowledge which the employee has gained from his experience. It thus becomes very important to have systems which make sure knowledge gained from experience is stored and is available for the successors. One of the main factors contributing towards a system failure is lack of overlapping when there is a job change. Delays in achievement of task can be avoided if there is better planning and adherence to documentation in a defined format to capture the knowledge gained by employee over a period of time. One example that is widely followed in $\mathrm{BOSCH}$ is that of Lesson learned. Every individual who learns something new through (Figure 14).

Experimentation or otherwise records the same in the Lessons Learned page at Bosch Intranet [10].

\section{Conclusion}

It has become a common sense that to sustain a business one needs to innovate. And it is also true that innovations have, in the past changed, changed the outlook of an entire industry be it that of manufacturing or service (Figure 15).

\section{Believe model}

Be leaders: "Good Leaders don't create followers they create Leaders". As described an Organizations develops its leaders in line with its values and ethics. A successful leader in these terms is one who is able to instill the same values and ethics in his colleagues. A leader takes failure on his part and gives the credit of success to his team and thus develops an environment of mutual co-operation and trust, indirectly cultivating the values. He sets examples, takes new initiatives thus moves a step towards innovation. He also makes people aware of their potential and suggests measures to overcome their weaknesses and hence educates them.

Innovations: What is innovation? Innovation is not necessarily a time booster or totally a new product. Innovation also means continuous improvements (Figure 16).

We have broadly classified innovation into three main categories,

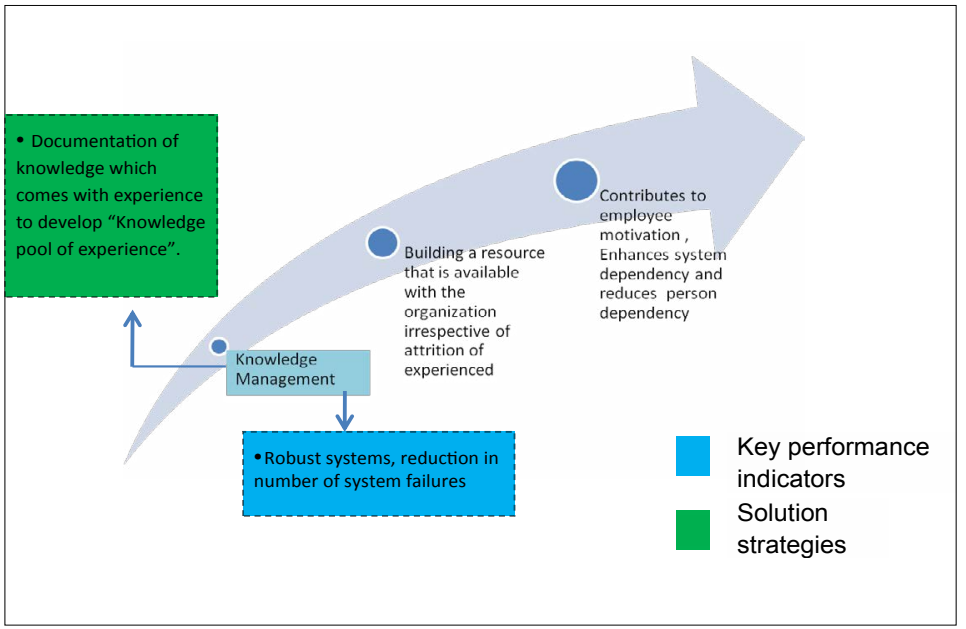

Figure 14: Key performance indicators \& strategies for knowledge management.

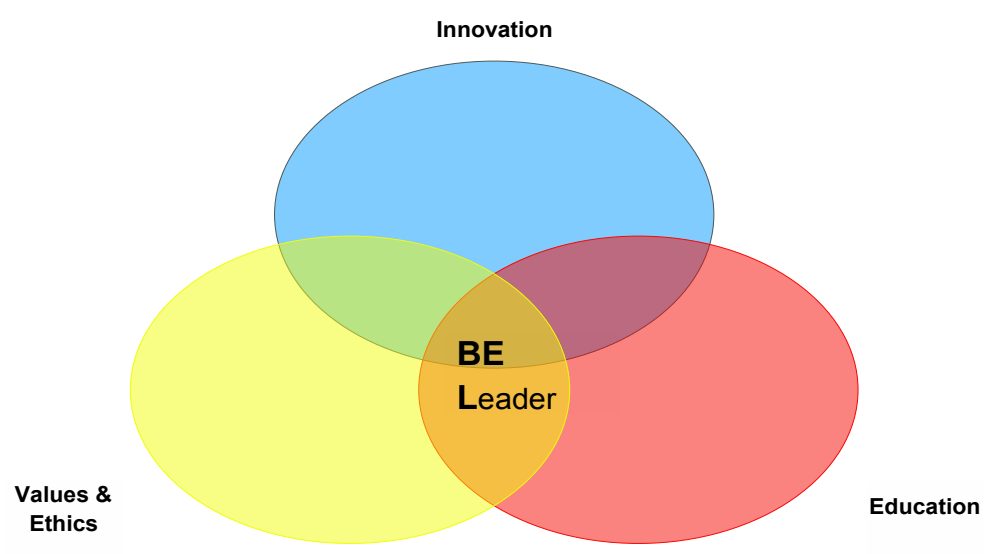

Figure 15: Believe model. 


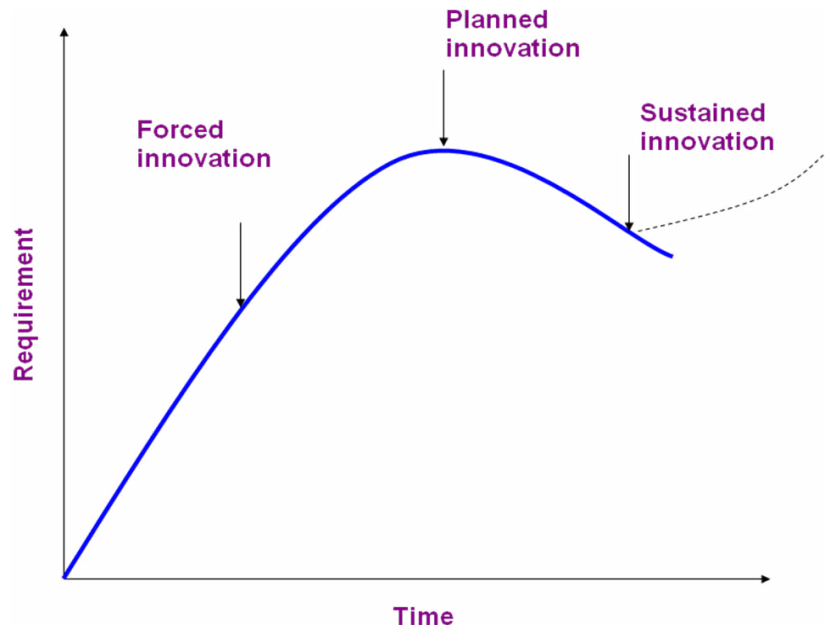

Figure 16: Type of Innovations.

Planned, Sustained and forced Innovations. Planned Innovations are those which an industry plans looking at the market scenario and thus formulating strategies accordingly for example a shift from mechanical pump to an electronically controlled pump. Sustained Innovations are those initiatives which a company does as a part of Continuous improvements. These kinds of innovations are broadly termed as continuous improvement projects for example waste elimination. Forced Innovations are those which are demand of the time, It means if one doesn't innovate the existence itself might go for a toss. Such situation may arise due to unawareness about the market trend. So an innovation is required but more important is the right type of innovation at the right time.

Educate: "Means to Enhance Quality of life". As for molding a child into a responsible citizen education is a basic requirement so is the requirement for Organizations to ensure regular transfer of knowledge from top to bottom levels so that everyone can contribute. Education is the process by which society deliberately transmits its accumulated knowledge, skills and values from one generation to another. The major challenge in front of all organizations is to bridge the gap between knowledge and its application and this can be done by practical trainings to strengthen knowledge application.

Through education

- Practical trainings and knowledge application should be strengthened so that young technocrats can apply their skills and contribute in providing new innovative solutions.

- Sharing knowledge within so that with mutual cooperation others can also reap benefit from it and can contribute to society.

- Employees having a broader mindset and vision will in turn result in empowered employees of empowered nation.

- Society is posed with a great challenge of terrorism and education is the one and only solution so that feelings of hatred, regionalism can be eliminated in the future generations of India.

Values and ethics: Values represent the strength of Organizations. It is something deep drilled and developed over a period of time, which in turn helps for the sustenance of Organizations in the long run. Bosch Group stands on 7 core values: Result and Future focus, Responsibility, Initiative and Determination, Openness and trust, Fairness, Reliability legality and Credibility and cultural diversity $[10,12]$.

All Organizations have values, what is different is the sincerity with which they follow the values. Organizations needs to educate its employee in lines with the values and then needs to evaluate them on the basis of the same.

\section{Executive Summary}

Be it on professional grounds or personal, to succeed one need to believe in what he does. Same is the case with an organization, challenges turn into opportunities when an organization \ believes in itself.

We propose a Believe model. In which we ourselves believe that only when the roots of an organization are those that have been strengthened trough education, values and ethics and nurtured by innovation, an organization can successfully grow.

\section{Be Leaders in innovation, education and values and ethics}

Approach: We have conducted a survey through which we have concluded the main challenges being faced by organizations in India. A brainstorming on why-why analysis lead us to the root causes of these challenges. Strategies give the solution and Key Performance Indicators help in monitoring the progress towards the goal. The organizational challenges have been listed down and the management challenges would be the formulation of strategies in order to accomplish the organizational challenges.

Believe made easy: While we have attempted to give a fair clarity on the individual elements with survey results and examples in the coming sections, it is important to note that the depth of implementation of individual elements can vary depending on the organization, area of application and resource allocations based on needs [1]

\section{Acknowledgement}

Our team would like to express sincere thanks to All India Management Association for providing us the opportunity to express our views on this topic at National Competition for Young Managers.

We thank Mr. Naveen B.V. (DGM - Quality Management) Bosch Limited and Mr. Ramamurthy K. (GM -Technical Engineering. Functions) Bosch Limited, Jaipur 
Citation: Chaturvedi J, Agarwal A, Patodia A (2018) Managing Organizational and Management Challenges in India. J Entrepren Organiz Manag 7: 235. doi: 10.4172/2169-026X.1000235

Page 11 of 11

for their guidance and valuable support throughout. We also thank Mr. Santosh Joseph, Senior Officer, Bosch Limited, Jaipur for his support

We also thank people across various industries in helping us by expressing their views through the survey conducted by the team. Results of the same have been presented at the relevant sections in the report.

\section{References}

1. Mouli C, Garg S (2009) Prosperity through Quality. Tokyo: Asian Network for Quality.

2. Srinivasan S (2010) Business article.

3. City Mayors 50 fastest growing urban areas.

4. Wilson D, Purushothaman R (2003) Dreaming with BRICs: The path to 2050 Global Economics Paper No.99, Goldman Sachs.

5. Commerce UD United States Census Bureau.
6. Bhat PNM (2003) Demographic Scenario 2025.

7. http://www.jasipurfoot.org/.

8. Prahalad CK, Hamel G (2006) The Core Competence of the Corporation. In Hahn D, Taylor B (EDS) Strategische Unternehmungsplanung - Strategische Unternehmungsfuhrung. Springer, Berlin, Heidelberg.

9. Bosch in India - Our Company.

10. https://www.bosch.in/our-company/bosch-in-india/jaipur-plant/.

11. Hourselt AS (2008) The Antidote - How to transform your business for the Extreme Challenges of the 21st Century.

12. Customer Complaint Management Team BJ (2010) Process Map for Customer Complaint Management.

13. http://wisdomfromsrisriravishankar.blogspot.in/2009/03/technology.html. 